\title{
A Multi-Scale Copper Oxide Film with Excellent Superhydrophobic Property on X90 Pipeline Steel
}

\author{
Li Hao $^{a}$, Yu Sirong ${ }^{\text {b }}$, Han Xiangxiang ${ }^{c}$ \\ College of Mechanical and Electronic Engineering, China University of Petroleum (East China), \\ Qingdao 266580, China \\ alihao89fly@163.com, byusrchina@163.com, ryanhan2015@163.com
}

\begin{abstract}
Keywords: Electrodeposition, solution-immersion, surface modification, multi-scale structure, superhydrophobicity.
\end{abstract}

\begin{abstract}
In this work, a multi-scale copper oxide film with excellent superhydrophobic property on X90 pipeline steel was fabricated by a combination method including electrodeposition, solution-immersion and chemical modification. Moreover, the influence of experimental parameters, such as solution-immersion time, chemical modification time and the concentration of $\left(\mathrm{NH}_{4}\right)_{2} \mathrm{~S}_{2} \mathrm{O}_{8}$, on the contact angle was studied, and the optimal experimental parameters were achieved. In addition, the surface morphology of the superhydrophobic copper oxide film was characterized by a scanning electron microscopy, and it showed that the multi-scale structure made up of micro flower-like or re-entrance structure and the secondary nano-sheet was obtained on the surface. The maximum contact angle between the water droplet and the superhydrophobic copper oxide film with the multi-scale structure was up to $158.55^{\circ}$.
\end{abstract}

\section{Introduction}

Superhydrophobic surface has attracted widespread attention due to its fundamental research and potential application values. Inspired by the lotus leaf, it was found that the surface morphology and the chemical composition both play important roles in achieving superhydrophobic property [1]. Recently, numerous methods [2] were used to fabricate the superhydrophobic surface with various surface morphologies. Moreover, solution-immersion method is often used to obtain the superhydrophobic surface due to its simple operation and low-cost [3]. In addition, the electrodeposition of copper coating was mainly used as the protective coating, improving the corrosion resistance of the substrate materials [4].

Pipeline steel is an essential metal material with widespread application in industrial production, especially the transportation. The adhesion of water mixture on steel surface directly affects the transport efficiency, resulting in energy waste, equipment damage, and many other problems. Therefore, it is necessary to fabricate a superhydrophobic surface on pipeline steel. In this work, the superhydrophobic copper oxide film with multi-scale structure was fabricated on X90 pipeline steel by a combination method including electrodeposition, solution-immersion, and chemical modification.

\section{Experimental}

Materials. X90 pipeline steel was used as substrate material, and the copper plate used as the counter electrode in the electrodeposition process. Moreover, anhydrous ethanol, acetone, $\mathrm{CuSO}_{4} \cdot 5 \mathrm{H}_{2} \mathrm{O}$, concentrated $\mathrm{H}_{2} \mathrm{SO}_{4}, \mathrm{KOH}$ and $\left(\mathrm{NH}_{4}\right)_{2} \mathrm{~S}_{2} \mathrm{O}_{8}$ were all analytical grade. Perfluorooctanoic acid with the low-surface-energy was used as modification.

Fabrication of Superhydrophobic CuO Film on X90 Pipeline Steel. The X90 pipeline steel substrate was first processed with pretreatment, including polished, alkaline and acid pickling, and cleaned, and the detailed introduction was reported in article [5]. Then, steel substrate (cathode) and the copper plate (anode) were immersed into the aqueous solution including $200 \mathrm{~g} / \mathrm{L}$ of $\mathrm{CuSO}_{4} \cdot 5 \mathrm{H}_{2} \mathrm{O}$ and $12 \mathrm{~g} / \mathrm{L}$ of concentrated $\mathrm{H}_{2} \mathrm{SO}_{4}$, and the distance of the electrode, the temperature of the electrodeposition solution, the current density, and the deposition time were set to $2 \mathrm{~cm}, 23^{\circ} \mathrm{C}$, 
$5 \mathrm{~A} / \mathrm{dm}^{2}$, and $30 \mathrm{~min}$, respectively. Next, the steel with copper coating was immersed into the aqueous solution containing $\mathrm{KOH}$ and $\left(\mathrm{NH}_{4}\right)_{2} \mathrm{~S}_{2} \mathrm{O}_{8}$ at $60^{\circ} \mathrm{C}$ for different times, ranging from 10 min to $300 \mathrm{~min}$. Finally, the steel with copper oxide film was modified by immersing into the 0.01 $\mathrm{mol} / \mathrm{L}$ of prfluorooctanoic acid ethanol solution, and then the sample was taken out after 7 days.

Characterizations. The water contact angle (CA) was measured with a water drop $(5 \mu \mathrm{L})$ using a contact angle meter (L200B, USA, KINO), and the following data were the average of three to five different positions. The crystal structure of the sample was recorded using X-ray diffraction (XRD, $X$ 'Pert PROMPD, PANalytical). In addition, the morphology of the specimen was investigated using SEM (Nova NanoSEM 450, FEI).

\section{Results and Discussion}

Effect of the Immersion Time in Solution-immersion Process on the CA. The steel surface with deposition copper coating immersed into the solution including $2.5 \mathrm{~mol} / \mathrm{L}$ of $\mathrm{KOH}$ and 0.1 $\mathrm{mol} / \mathrm{L}$ of $\left(\mathrm{NH}_{4}\right)_{2} \mathrm{~S}_{2} \mathrm{O}_{8}$ at $60^{\circ} \mathrm{C}$ for different times (from $10 \mathrm{~min}$ to $300 \mathrm{~min}$ ) and then modified with $0.01 \mathrm{~mol} / \mathrm{L}$ of prfluorooctanoic acid ethanol solution for 7 days. Fig. 1 shows the water CA of the sample surface changed with the immersion time. It can be found that the CA increased with the increase of the immersion time, and it was up to $156.05^{\circ}$ when the time was $50 \mathrm{~min}$. Then, the CA slightly decreased when the immersion time continued to increase although it was still larger than $150^{\circ}$. Therefore, the optimal immersion time was $50 \mathrm{~min}$ to achieve superhydrophobic film.

Effect of the Modification Time on the CA. The sample with copper coating immersed into the solution including $2.5 \mathrm{~mol} / \mathrm{L} \mathrm{KOH}$ and $0.1 \mathrm{~mol} / \mathrm{L}\left(\mathrm{NH}_{4}\right)_{2} \mathrm{~S}_{2} \mathrm{O}_{8}$ at $60^{\circ} \mathrm{C}$ for $50 \mathrm{~min}$ and then modified with $0.01 \mathrm{~mol} / \mathrm{L}$ of prfluorooctanoic acid ethanol solution for different times, ranging from 3 days to 13 days. As shown in Fig. 2, the CA increased with rising the time, and it was up to $156.52^{\circ}$ once the time was 7 days. Then, the CA was stable at about $156^{\circ}$ with further growing the modification time. With the increase of immersion time, the physical adsorption of the prfluorooctanoic acid improved. Once the time up to 7 days, the adsorption almost was saturation. Therefore, the CA was unchanged with the growing immersion time. It indicated that the optimal and shorter modification time was 7 days.

Effect of the Concentration of $\left(\mathrm{NH}_{4}\right)_{2} \mathrm{~S}_{2} \mathrm{O}_{8}$ on the CA. The influence of the concentration of $\left(\mathrm{NH}_{4}\right)_{2} \mathrm{~S}_{2} \mathrm{O}_{8}$ on the CA was shown in Fig. 3. The sample with copper coating was immersed into the solution including $2.5 \mathrm{~mol} / \mathrm{L}$ of $\mathrm{KOH}$ and different concentrations of $\left(\mathrm{NH}_{4}\right)_{2} \mathrm{~S}_{2} \mathrm{O}_{8}$ (from 0.04 $\mathrm{mol} / \mathrm{L}$ to $0.24 \mathrm{~mol} / \mathrm{L}$ ) at $60^{\circ} \mathrm{C}$ for $50 \mathrm{~min}$ and then modified with $0.01 \mathrm{~mol} / \mathrm{L}$ of prfluorooctanoic acid ethanol solution for 7 days. According to Fig. 3, at the beginning, the CA increased with increasing the concentration, peaking at around $158.55^{\circ}$ at the concentration of $0.12 \mathrm{~mol} / \mathrm{L}$. However, the CA declined dramatically when further increased the concentration. Moreover, when the concentration rose to $0.24 \mathrm{~mol} / \mathrm{L}$, the CA was only $141.83^{\circ}$, and the water droplet would spread out on the surface over time. Finally, the optimal concentration of the $\left.\mathrm{NH}_{4}\right)_{2} \mathrm{~S}_{2} \mathrm{O}_{8}$ was obtained, and it was $0.12 \mathrm{~mol} / \mathrm{L}$.

Effect of the Solution-immersion on the Crystal Structure of Copper Deposition. To study the influence of the solution-immersion on the crystal structure of the copper coating, the XRD pattern of the copper coating immersed into the mixed solution of $2.5 \mathrm{~mol} / \mathrm{L}$ of $\mathrm{KOH}$ and $0.1 \mathrm{~mol} / \mathrm{L}$ of $\left(\mathrm{NH}_{4}\right)_{2} \mathrm{~S}_{2} \mathrm{O}_{8}$ at $60^{\circ} \mathrm{C}$ for 50 min was given in Fig. 4. It can be found that $\mathrm{CuO}$ peaks can be well indexed to JCPDS Card No. 03-065-9026. In other words, there was copper oxide film forming on the deposition copper coating. Besides, the orientation of (-111) and (200) was relatively strong, therefore, the $\mathrm{CuO}$ crystallites had a preferential orientation, resulting in the nano-sheets that composed the flower-like structure (Fig. 5). Moreover, the peaks of $\mathrm{Cu}$ also appearing in the as-prepared surface were only driven from the original deposition copper coating, which indicated that the $\mathrm{CuO}$ film was very thin that was consistent with article [6]. 


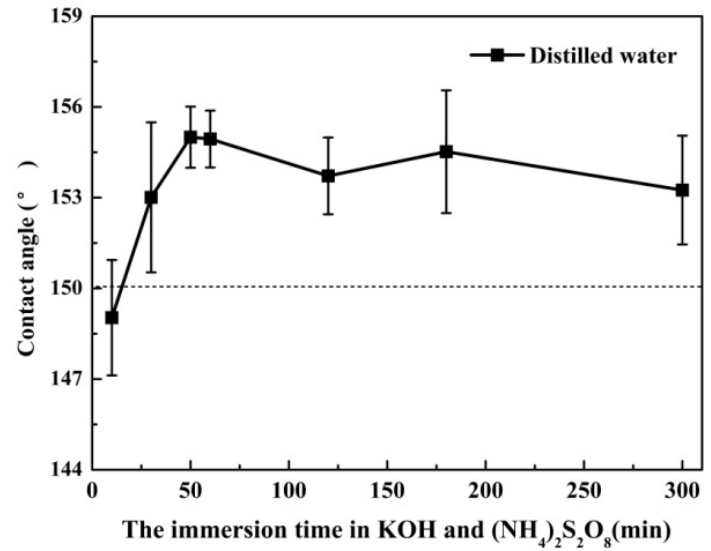

Fig. 1 Effect of solution-immersion time on the contact angle (from $10 \mathrm{~min}$ to $300 \mathrm{~min}$ )

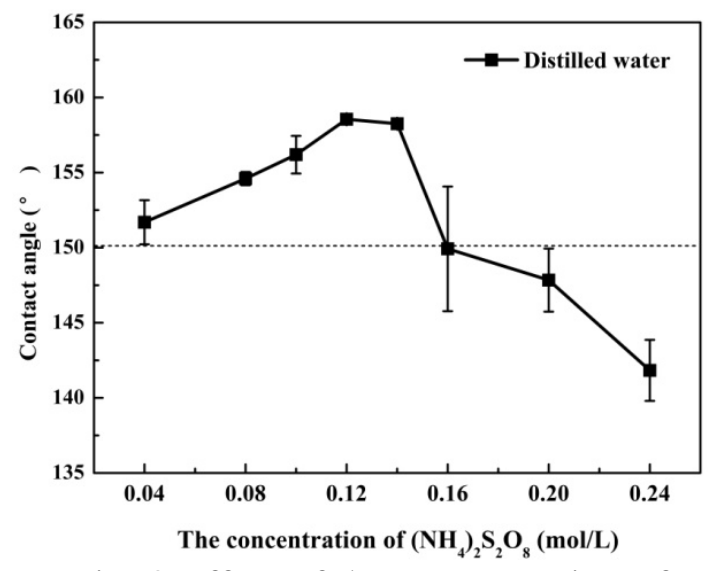

Fig. 3 Effect of the concentration of $\left(\mathrm{NH}_{4}\right)_{2} \mathrm{~S}_{2} \mathrm{O}_{8}$ on the contact angle

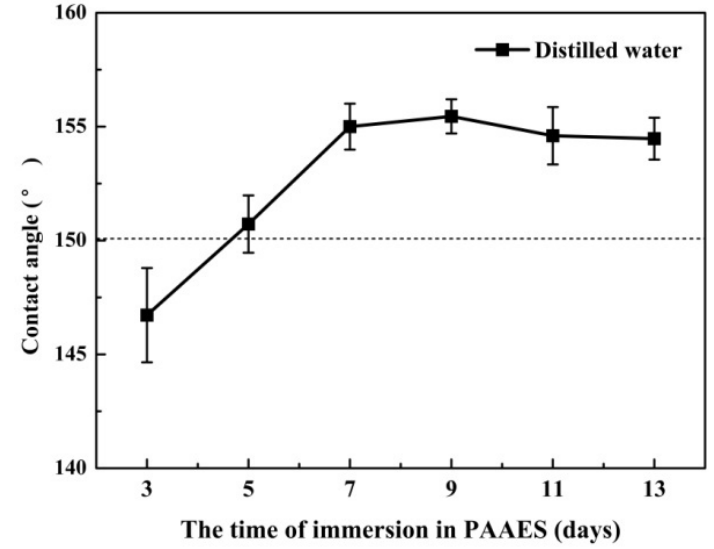

Fig. 2 Effect of the modification time in

PAAES (prfluorooctanoic acid ethanol solution) on the contact angle

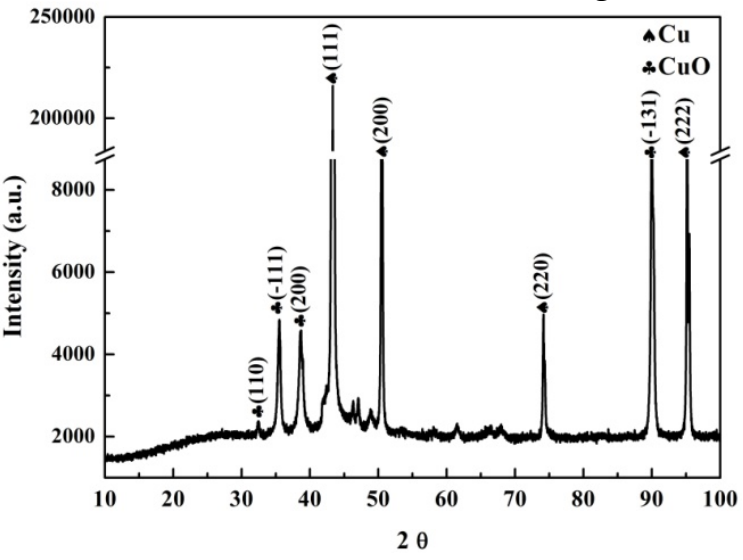

Fig. 4 XRD pattern of the copper coating after processed with solution-immersion.

Morphology of the Superhydrophobic Copper Oxide Film. The superhydrophobic copper oxide film was achieved by immersing the steel surface with copper coating into the solution including $2.5 \mathrm{~mol} / \mathrm{L}$ of $\mathrm{KOH}$ and $0.12 \mathrm{~mol} / \mathrm{L}$ of $\left(\mathrm{NH}_{4}\right)_{2} \mathrm{~S}_{2} \mathrm{O}_{8}$ at $60^{\circ} \mathrm{C}$ for $50 \mathrm{~min}$ and then modified with $0.01 \mathrm{~mol} / \mathrm{L}$ of prfluorooctanoic acid ethanol solution for 7 days. As shown in Fig. 5, there were numerous one-dimensional nano-sheets on the surface. In addition, some nano-sheets self-organizing into micro flower-like structures distributed uniformly on the surface, and most nano-sheets were formed into re-entrance structures. Therefore, the multi-scale structure that was made up of micro flower-like or re-entrance structure and the secondary nano-sheet was obtained on the surface. The multi-scale was beneficial to the formation of air pocket that stabilized the droplets [7]. Moreover, the CA on the coating was stable, still larger than $150^{\circ}$, after exposure more than 6 months. It was demonstrated that the superhydrophobic surface processed durability in atmospheric environment.

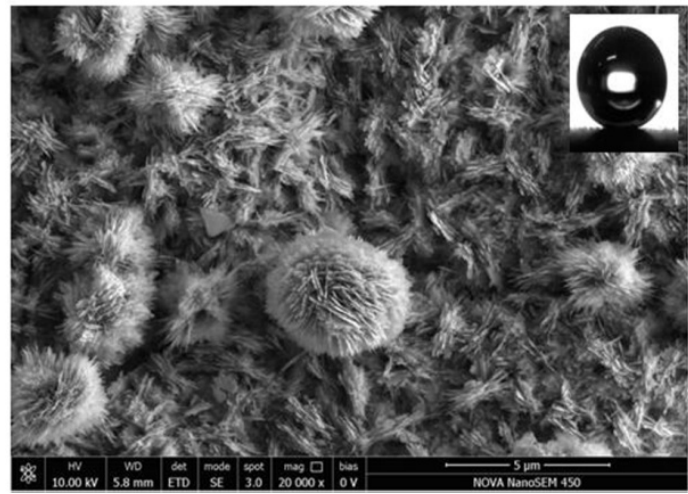

Fig. 5 Morphology of the superhydrophobic copper oxide film 


\section{Conclusion}

A superhydrophobic copper oxide film with multi-scale structures was successfully obtained on X90 pipeline steel, and the water contact angle of the surface reached a maximum of $158.55^{\circ}$. Moreover, the optimal experimental parameters were achieved, including the solution-immersion time (50 min), chemical modification time ( 7 days), and the concentration of $\left(\mathrm{NH}_{4}\right)_{2} \mathrm{~S}_{2} \mathrm{O}_{8}(0.12$ $\mathrm{mol} / \mathrm{L}$ ). In addition, the contact angle on the superhydrophobic surface was stable after exposure more than 6 months, which demonstrated that this surface processed durability in atmospheric environment. Therefore, it can provide a way to the utilization of deposition coating in numerous applications, including superhydrophobic surface.

\section{Acknowledgements}

This work was supported by the financial support of the National Natural Science Foundation of China (No. 51075184), and the Fundamental Research Funds for the Central Universities (No. 15CX06059A).

\section{References}

[1] W. Barthlott, C. Neinhuis: Planta Vol. 202 (1997), p. 1-8

[2] D. Zhu, X. Lu, Q. Lu: Langmuir Vol. 30(2014), p. 4671-4677

[3] Y.F. Chung, M.Z. Chen, S.H. Yang, S.C. Jeng: ACS Appl. Mater. Interfaces Vol. 7 (2015), p. 9619-9624

[4] T. Yin, R. Wu, Z. Leng, G. Du, X. Guo, M. Zhang, J. Zhang: Surf. Coat. Technol Vol. 225 (2013), p. 119-125

[5] H. Li, S.r. Yu, X. X. Han: New J. Chem. Vol. 39 (2015), p. 4860-4868

[6] J. Li, X. Liu, Y. Ye, H. Zhou, J. Chen: J. Phys. Chem. C Vol. 107 (2011), p. 4726-4729

[7] M. Nosonovsky, B. Bhushan: Ultramicroscopy Vol. 107 (2007), p. 969-979 